\section{Neuropsicologia, teoria e prática}

\author{
Fuentes D, Malloy-Diniz LF, Camargo CHP, Cosenza RM,
} et al. Artmed; 2007. 432 p. ISBN: 8536311193

O livro Neuropsicologia, teoria e prática parece contemplar muito bem o que se propõe em seu título. Nele encontramos 26 capítulos que tratam sobre os aspectos mais diversos no que tange à atualidade da neuropsicologia. Trata-se de um livro didático, porém aprofundado nos temas que se propõe, abordando uma ampla faixa de matérias no que concerne à neuropsicologia.

Neste sentido, um livro com esta estrutura é bastante desafiador, uma vez que a neuropsicologia é recente no Brasil, embora estudos ligando cérebro às emoções sejam antigos, remontando, por exemplo, a Hipócrates. Apesar da referida brevidade, concomitantemente, seu quadro epistemológico se alterando rapidamente devido a descobertas, técnicas inovadoras e aprofundamentos transdisciplinares.

No prefácio, Paulo Mattos (presidente da Sociedade Brasileira de Neuropsicologia) traz uma preocupação com visão a mecânica que se tem do emprego de testes neuropsicológicos, fazendo o contraponto de que neuropsicologia é um exame clínico armado. Isto se dá uma vez que a neuropsicologia abarca a necessidade de uma amplitude de conhecimentos multidisciplinares e, igualmente, um aprofundamento na especificidade na contribuição de cada área.

Este livro delimita justo este aspecto, demarcando a ampla gama de aplicações da neuropsicologia na área de pesquisa e na área clínica, expandindo sua atuação e a interface com outras áreas. As aplicações da neuropsicologia têm se ampliado na medida em que se aprofundam os conhecimentos nas áreas que the circundam, bem como, nos últimos anos, o arsenal de testagens neuropsicológicas vêm se multiplicando e dando conta de necessidades mais específicas.

Visando contemplar esta demanda da atualidade, o livro Neuropsicologia, teoria e prática agrega autores de diferentes áreas e aborda temas de relevância clínica a partir da ótica de bem conceituados profissionais.

Os capítulos tratam de temas diversos e possuem uma estrutura que, em sua maioria, comporta um resgate histórico e conceitual do tema abordado, para posteriormente embargar em um aprofundamento atualizado dos tópicos referentes à temática.

Já no primeiro capitulo, é considerada justamente a dimensão relacional entre sistema nervoso e funções cognitivas e comportamentais, a partir de um resgate histórico que remonta aos primórdios da neuropsicologia, retomando desde Aristóteles com suas tentativas de entender o funcionamento mental. Posteriormente, o livro segue apresentando a perspectiva neurobiológica do comportamento humano e descrevendo a organização morfofuncional do sistema nervoso, desde sua estruturação neuronal e ontogene.

O livro também aborda a questão de como as experiências individuais e a interação ambiental modulam as tendências genéticas. Ainda, traz noções de psicometria, métodos de neuroimagem estrutural e funcional (auxiliares no diagnóstico de distúrbios neurológicos) e do exame neuropsicológico e seus diferentes contextos de aplicação.

O livro versa também sobre as funções de neuroaudiologia e linguagem, desenvolvimento das habilidades de leitura e escrita, memória, funções executivas e comportamento motor.

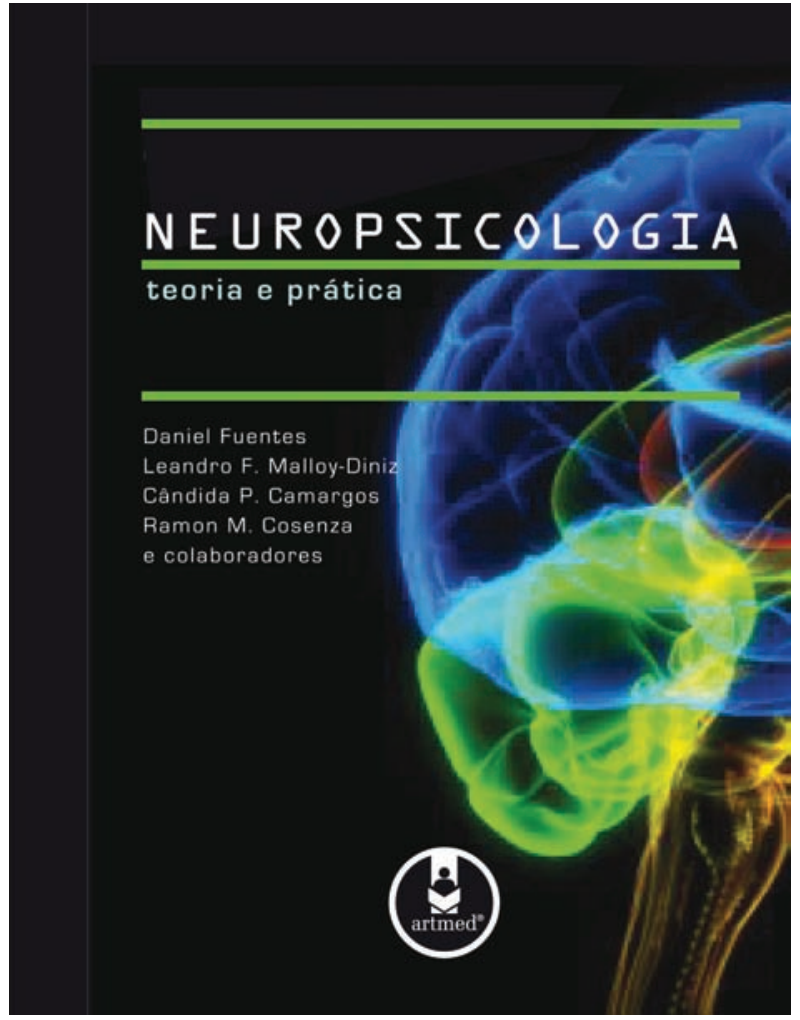

Traz a neuropsicologia de diversas patologias emocionais e fisiológicas, como afasias, déficit de atenção e hiperatividade, transtorno do humor bipolar, esquizofrenia, cefaléias, transtorno obsessivo-compulsivo, jogo patológico, neuropsiquiátricos e neuropsicológicos da infecção pelo HIV e da AIDS, e a neuropsicologia e avaliação neuropsicológica das demências.

Os capítulos finais dissertam sobre a vida prática, a reabilitação neuropsicológica e as novas tecnologias no que concerne a reabilitação neuropsicológica. Por fim, o capítulo 26 trata sobre a neuropsicologia no Brasil, trazendo sua interface com diferentes áreas, bem como trata sobre a tecnologia e as perspectivas que amplia para a neuropsicologia e sobre neuropsicologia e educação; além de abordar a questão da cognição social e as novas funções emocionais junto com as suas localizações cerebrais, descobertas pela ressonância magnética. As autoras também falam sobre a Sociedade Brasileira de Neuropsicologia (que objetiva a difusão das ciências neuropsicológicas em nível nacional).

Portanto, trata-se de um livro completo, escrito por profissionais de destaque e ideal para profissionais das mais diversas áreas que tangem e se interligam com a neuropsicologia.

Natália Soncini Kapczinski

Psicóloga clínica, Hospital de Clínicas de Porto Alegre (HCPA), Porto Alegre (RS), Brasil

Joana Corrêa de Magalhães Narvaez

Psicóloga clínica, Programa de Transtorno do Humor Bipolar (PROTAHBI), Hospital de Clínicas de Porto Alegre (HCPA), Porto Alegre (RS), Brasil 